\title{
A TRAJETÓRIA DO CONCEITO DE GENEALOGIA EM FOUCAULT (1971- $1984)^{1}$
}

\section{Luiz Celso Pinho (UFRRJ) ${ }^{2}$}

lucepi@uol.com.br

Resumo: Neste ensaio se pretende assinalar as diversas modulações pelas quais passa o conceito nietzschiano de genealogia na obra de Michel Foucault ao longo das décadas de 1970 e 1980 . Deste modo, será possível mostrar que o procedimento genealógico se modifica em função da temática abordada, isto é, este não parte dos mesmos pressupostos teóricometodológicos quando tem por meta: a rejeição da noção metafísica de uma origem essencial; a pressuposição recíproca entre o Saber e o Poder; o projeto de transformar a vida humana numa espécie de obra de arte; e, finalmente, elaborar uma ideia de verdade dissociada de parâmetros lógicos, epistemológicos ou ontológicos.

Palavras-chave: história; poder; ética; verdade.

Em seu clássico e original estudo sobre a arqueologia foucaultiana, Roberto Machado aborda a especificidade de cada etapa das investigações realizadas ao longo dos anos 60 . Referimo-nos a História da loucura na época clássica (1961), O nascimento da clínica (1963), As palauras e as coisas (1966) e A arqueologia do saber (1969). Tomando o aparato metodológico da epistemologia histórica francesa como referência, Ma-

\footnotetext{
${ }^{1}$ Recebido: 25-10-2013/Aprovado: 18-08-2014/Publicado on-line: 08-09-2014.

${ }^{2}$ Luiz Celso Pinho é Professor Adjunto IV na Universidade Federal Rural do Rio de Janeiro, Campus Seropédica, RJ, Brasil.
} 
chado ressalta que o empreendimento arqueológico se caracteriza pela "multiplicidade de suas definições, [pela] mobilidade de uma pesquisa que [evita] se fixar em cânones rígidos, [enfim, por seu] caráter provisório [...]" (MACHADO 2006, 12).

Essa leitura nos leva a refletir sobre o estatuto teórico da genealogia em obras como Vigiar e punir (1975), A vontade de saber (1976), O uso dos prazeres (1984), O cuidado de si (1984) e nos diversos cursos realizados no Colégio de França que lhes serviram de preparação. Alguns intérpretes recorrem ao preceito da "afinidade eletiva" (THIELE 1990; GEISS 1993; ANSELL-PEARSON 1995) entre Nietzsche e Foucault. Além disso, Michel Mahon aplica indistintamente a genealogia nietzschiana às problematizações foucaultianas do Saber, do Poder e da Ética (MAHON 1992). No mesmo sentido dessa abordagem generalizante, Alan Schrift considera que existe um vínculo direto entre os principais eixos norteadores da obra de Foucault - Discurso, Verdade, Poder, Sujeito - e o legado nietzschiano, o que indicaria uma ininterrupta continuidade entre as pesquisas arqueológicas, genealógicas e éticas (SCHRIFT 1995). Alasdair MacIntyre (1994, 302), por sua vez, sustenta que Foucault realiza uma "aplicação parcial" do programa genealógico nietzschiano.

Aproximamo-nos da leitura de John Rajchman, para quem "a 'genealogia' de Nietzsche forneceu um modelo [de escrita da história]" às análises crítico-documentais de Foucault a partir de 1971 (RAJCHMAN 1985, 5). Consideramos que tal abordagem se mostra mais fiel à letra do pensador francês, pois considera que Foucault "não apresenta simplesmente um comentário sobre Nietzsche, usa também Nietzsche para repensar e reformular seu próprio 
trabalho" (RAJCHMAN 1985, 115). Também cabe destacar a cautela de Judith Revel: "mais do que uma referência, trata-se de retraçar um desenvolvimento, ou seja, de uma reapropriação que não se limita nem à exegese tranquila nem à escolha de uma posição filosófica" (REVEL 2010, 87).

Mas, antes de enveredarmos pelos escritos históricofilosóficos de Foucault no período que se estende entre 1971 e 1984, faz-se necessário um breve exame do que vem a ser o procedimento genealógico no opus nietzschiano. A rigor, ele só é empregado nominalmente na argumentação de Genealogia da moral (1887), apesar de no Prefácio deste haver indicações que remetem às páginas do primeiro volume de Humano, demasiado humano (1876). Como o próprio Nietzsche enuncia, a análise genealógica se aplica à elucidação de três origens: da dicotomia bom/mal, da má consciência e do ideal ascético. Sendo que cada uma delas remete a um tipo de homem "decadente": o ressentido, incapaz de adotar uma postura criadora; o culpado, fadado a viver em dívida, atormentado por promessas; e o que anseia pelo Nada ao conceber uma realidade suprassensível. Estamos diante de uma noção aplicável a aspectos distintos da existência humana.

Mas isso não esgota a riqueza da noção nietzschiana de genealogia. As caracterizações acima pretendem explicitar estados de saúde ou de doença. Daí o filósofo-médico realizar um diagnóstico que toma por referência a "primazia fundamental das forças espontâneas, agressivas, expansivas, criadoras de novas formas, interpretações e direções" (NIETZSCHE 1988, 82). Tal princípio metodológico serve de base para o entendimento de como se constituem não apenas as relações sociais como também o tipo de impulso 
que sustenta o pensamento filosófico, religioso, político, artístico, em suma, a cultura ocidental como um todo. O que importa é justamente detectar um enfraquecimento ou fortalecimento da Vontade de Potência, isto é, da Vida. Ou ainda, de acordo com Deleuze, "o que interessa [a Nietzsche] é a diversidade das forças ativas e reativas, a busca das forças ativas" (DELEUZE 1962, 47).

A análise genealógica volta-se, assim, para a elucidação dos "preconceitos morais" operantes, por exemplo, na formação do Sujeito: seja através da interiorização da culpa promovida pelo Sacerdote, seja pela necessidade de o Estado reprimir os instintos em nome de um pacto que favoreça a existência gregária. Cabe destacar também que a noção de Verdade deixa de ser examinada a partir de um referencial ontológico e essencialista para fazer parte de um mecanismo de desvalorização do Tempo, do Devir, de tudo aquilo que se mostra transitório e, por isso mesmo, "mundano". Tratase de dissecar as baixas origens do discurso verdadeiro. É preciso salientar que essa nova forma de valoração requer uma concepção dinâmica dos processos históricos, onde prevalece o embate constante, a ausência de finalidades preestabelecidas e a recusa de qualquer referencial antropológico.

$$
* * *
$$

Com o Foucault genealogista verificamos a passagem da região da Moral para a problematização do Poder. Esse deslocamento introduz na análise histórica, política e epistemológica a chamada "hipótese Nietzsche", cuja ideia central reside na premissa de que a "base de toda relação de poder [é atravessada pelo] confronto belicoso das forças" (FOUCAULT 1997, 17). Fica patente que, para ambos, a efetiva compreensão do modo de ser das coisas requer a adoção de uma perspectiva agonística, pois o destino de to- 
do existente - e aqui não cabe a distinção entre instância biológica, sociológica ou psicológica - encontra-se regido por uma luta incessante.

Não almejamos, contudo, investigar de que modo Foucault se aproxima, se superpõe, se afasta ou, para utilizar uma célebre expressão cunhada por ele, "faz ranger" o legado nietzschiano. Nosso objetivo reside em examinar a dinâmica interna da argumentação foucaultiana nas décadas de 1970 e 1980, tomando como fio condutor as diversas modulações pelas quais passa o procedimento genealógico, tanto nos seus trabalhos sobre os dispositivos disciplinares e confessionais quanto nos cursos proferidos no Colégio de França. Daí termos como ponto de partida a seguinte problemática: Até que ponto poderíamos afirmar que o "método" genealógico teria um sentido unívoco em torno das relações de saber-poder que permeiam e constituem as práticas - discursivas, sociais e de si - dos indivíduos? Encontramos um indicativo relevante para dar conta dessa indagação quando Foucault declara no início do curso "É preciso defender a sociedade" (1976) que realizou, nos últimos cinco anos, "pesquisas genealógicas múltiplas" (FOUCAULT 1997, 9), compostas de "fragmentos" (FOUCAULT 1997, 12), marcadamente "dispersas" (FOUCAULT 1997, 13) e que envolvem sempre uma "definição provisória” (FOUCAULT 1997, 10). Essas breves indicações nos sugerem que a genealogia foucaultiana também se mostra irredutível a um denominador comum, ou seja, também obedece ao "princípio" arqueológico da mobilidade.

É nesse sentido que se pretende assinalar as necessidades e os impasses teórico-metodológicos que levaram a sucessivas e sutis inflexões entre 1971 e 1984. Partiremos, 
assim, da hipótese de que os pressupostos históricofilosóficos da investigação genealógica de Foucault se modificam em função da problemática abordada. Destacamos os seguintes momentos: a recusa da pesquisa metafísica da origem, a defesa da pressuposição recíproca entre Saber e Poder, a proposta de transformação da vida humana numa obra de arte e, finalmente, a estratégia de não avaliar a "verdade" em função de parâmetros lógicos, ontológicos ou epistemológicos.

A ordem do discurso (1971) apresenta, pela primeira vez, passagens que sinalizam a preocupação em estabelecer o que podemos entender - deixando de lado o estigma unificador, monolítico e doutrinário atribuído à noção de teoria ${ }^{3}$ - como sendo o esboço de uma Teoria da História de base genealógica. Isso fica patente através da proposta (dispersa e abrangente) de conceber o devir histórico a partir da diretriz programática de acontecimentos descontínuos, anônimos, dispersos e casuais. Nesse contexto, Foucault considera que o papel da Genealogia - que, deve-se ressaltar, nesse momento desempenha uma função complementar em relação à Arqueologia - "diz respeito à formação efetiva dos discursos" (FOUCAULT 1971, 67), o que requer que se leve em conta tanto "jorro espontâneo dos discursos" quanto os "mecanismos de exclusão" (FOUCAULT 1971, 68).

Este segundo aspecto - de teor inicialmente "negativo"

\footnotetext{
${ }^{3}$ Apesar da recusa de Foucault em elaborar um corpus teórico estruturalmente articulado, um modelo explicativo genérico dos mais diversos acontecimentos, ele assinala que, do ponto de vista genealógico, "não se trata de opor a unidade abstrata da teoria à multiplicidade concreta dos fatos" (FOUCAULT 1997, 10). Lição importante, tendo em vista que fomenta justamente a "insurreição [...] contra os efeitos de poder centralizadores" (Ib.). A ênfase no caráter fragmentário da genealogia serve, pois, de antídoto às pretensas evidências do pensamento totalizante.
} 
- adquire maior expressão no resumo do curso de 1971, “A vontade de saber", onde as transformações das práticas discursivas estão vinculadas a uma concepção de "conhecimento fundamentalmente interessado, produzido como acontecimento do querer e determinando, por meio de falsificação, o efeito de verdade" (FOUCAULT 1994a, 244). Tal perspectiva torna-se mais consistente com a crítica feita à pesquisa metafísica das origens em "Nietzsche, a genealogia, a história” (1971). Nesse ensaio, sobressai-se a intenção de vincular o procedimento genealógico - originalmente concebido na análise nietzschiana da moral para como se deu o surgimento da dicotomia de valores, da formação da consciência e da crença num além-mundo -, tanto a um uso "destruidor da realidade [...] da identidade [...] [e] da verdade" quanto se libertar de um "modelo, ao mesmo tempo metafísico e antropológico, de memória” (FOUCAULT 1994b, 152-153).

Tem-se, com isso, uma concepção de escrita da história que almeja, simultaneamente, desvencilhar-se de qualquer laço com o preceito de reminiscência platônica ou, como já havia sido enunciado desde o período da Arqueologia do Saber, com o pressuposto de um sujeito a-histórico, de base hegeliana ou fenomenológica. Foucault se apropria da rubrica genealogia para romper com algumas certezas da tradição filosófica. Através da primeira torna-se possível dissipar as identidades - inclusive a do próprio homem - e fazer aflorar as multiplicidades. O "bom historiador" será aquele que é capaz de "promover [mettre en oeuvre] um grande carnaval do tempo, onde as máscaras não cessam de retornar" (FOUCAULT 1994b, 153). Deste modo, a história genealógica nos permite reconhecer "que vivemos, sem referências nem coordenadas, numa miríade de acontecimen- 
tos perdidos" (FOUCAULT 1994b, 149-150). Ao adotar um referencial nietzschiano para fundamentar sua Teoria da História, Foucault almeja multiplicar, fragmentar e tornar acidentado um percurso antes concebido de forma idealmente linear e orientada para um fim determinado.

A genealogia foucaultiana se norteia pela convicção de que Nietzsche é o "melhor, mais eficaz e atual" modelo para a análise das relações de poder no mundo ocidental (FOUCAULT 1996, 9). Daí Foucault afirmar logo na primeira aula de "É preciso defender a sociedade" (1976) que pretende "analisar o poder político como guerra" (FOUCAULT 1997, 19), ou seja, levando em consideração a entrada em cena de táticas, estratégias e relações de luta e força a partir das quais irrompem - como se poderá constatar nas análises histórico-filosóficas vindouras - novas configurações no campo dos saberes, das formas de governo e das modalidades éticas de relação consigo. Após ter servido de base para a criação de uma nova imagem dos processos históricos, o procedimento genealógico passa a retratar, nas pesquisas foucaultianas sobre a formação de saberes sobre o indivíduo, a aliança entre formas de conhecimento e interesses políticos. Produz-se, assim, uma "subversão da relação entre poder e conhecimento ou entre poder e verdade" (CALOMENI 2004, p. 75)

Foucault dá início ao projeto de elaborar uma Genealogia do Poder a partir das noções de positividade, produtividade e estratégia. Tal empreendimento não consiste, como facilmente se poderia concluir, em resgatar o conceito nietzschiano de Vontade de Potência no intuito de mostrar sua ação efetiva no campo das relações sociais cotidianas. Também não se trata de propor que a produção de Saber aumenta o 
domínio do Poder e vice-versa, tese que já foi defendida por Hobbes. A análise genealógica instaura, nesse momento, uma forma de inteligibilidade dos mecanismos que fazem interagir entre si a dimensão antropológica, a verdade que dela se extrai e a funcionalidade política daí resultante. Mas esse processo se desdobra em duas direções complementares: dar conta das condições de possibilidade do Sujeito, num primeiro momento; e do Estado, num segundo momento. E, em ambos os casos, o exercício do Poder Político é explicado tomando como referência o modelo nietzschiano do jogo de forças. ${ }^{4}$

$* * *$

Do ponto de vista programático, a analítica foucaultiana dos dispositivos de poder responde a uma questão que remonta ao período arqueológico. Por isso a recusa de que o homem seria a mais antiga problemática do pensamento ocidental, o elemento diferencial em relação às demais culturas. Também não o considera o fundamento do Saber, da Liberdade, da Linguagem ou da História. Nietzsche inscreve o sujeito numa temporalidade que lhe atravessa e constitui, descobrindo na moralidade judaico-cristã o operador externo dessa transformação. Foucault, por sua vez, ao romper com os pressupostos antropológicos de unidade e fundamento e privilegiar as figuras do múltiplo e do heterogêneo, elege não a moral, mas manobras, técnicas e discursos que agem de forma indiscreta e silenciosa, e que, além disso, têm por meta observar, treinar, examinar e corrigir os indivíduos. Não deixa de ser uma engrenagem moralizadora.

\footnotetext{
${ }^{4}$ Uma diferença que precisa ser ressaltada é que enquanto o filósofo alemão acaba retratando um aspecto "cosmológico", Foucault delimita o alcance de suas proposições no campo da História das Ciências, mais exatamente nos mais diversos saberes a respeito do "homem".
} 
Porém, a genealogia foucaultiana se detém nos mecanismos extraepistemológicos de normalização das condutas e dos desejos para relacionar como essa modalidade de controle serve de apoio para a constituição de um novo campo de saber - as Ciências Humanas.

Graças à crescente tendência, a partir do final do século XVIII, verificada nos campos os mais diversos - pedagógico, militar, industrial, correcional etc. - de segmentar, combinar, serializar, analisar e examinar, é que se pode depreender que "o poder produz; produz o real; produz domínios de objetos e rituais da verdade. $\mathrm{O}$ indivíduo e o conhecimento que dele se pode obter resultam dessa produção" (FOUCAULT 1975, 227). Através de uma perspectiva genealógica, delineia-se a imagem de um homem que naturalmente obedece, já que se tornou dócil aos comandos e regras, e confessa os "pecados" da carne, na medida em que precisa descobrir sua identidade ou deixar de ser o que até então era. Através desse quadro misto de incremento e coerções, aptidões e classificações, no qual se dá o início da modernidade, Foucault se pergunta se não é preciso "considerar que a política não é a guerra continuada por outros meios" (FOUCAULT 1976, 123). A analítica foucaultiana do poder ressalta, assim, num primeiro momento, o projeto de uma sociedade estruturada por mecanismos de controle do tipo carceral ou militar. O que o leva a ressaltar o quanto a prisão se assemelha ao cotidiano da fábrica, da escola, do quartel, do hospital, e que "todos se pareçam com as prisões” (FOUCAULT 1975, 164).

Desde as primeiras aulas de "É preciso defender a sociedade" Foucault reforça o aspecto militarista das sociedades disciplinares, o que o leva a considerar "a teoria da guerra como 
princípio histórico de funcionamento do poder" (FOUCAULT 1997, 19), "matriz das técnicas de dominação" (FOUCAULT 1997, 40), "fundamento das relações sociais" (FOUCAULT 1997, 42). Em Segurança, território e população (1978), quando se refere ao tipo de análise que realizou com as instituições de sequestro (notadamente asilares e penitenciárias), salienta que a "genealogia não deve ser confundida com gênese e filiação, pois reconstrói toda uma rede de alianças, comunicações e pontos de suporte. Logo, o primeiro princípio metodológico consiste em sair da instituição para substituí-la pelo ponto de vista global da tecnologia do poder" (FOUCAULT 2004, 162-163).

Nesse momento da trajetória do pensamento foucaultiano aprofunda-se a passagem da "anátomo-política" para a "biopolítica", 5 ou seja, da transição de uma genealogia do corpo-máquina para uma genealogia do corpo-espécie. Não se trata exclusivamente de uma alteração na abrangência dos mecanismos de vigilância das condutas: da multiplicidade restrita de corpos para todo um contingente humano, mas sim de "um modo próprio de agenciamento do espaço, uma forma precisa de normalização, assim como a singularização de um corpo específico" (FONSECA 2008, 242). Ora, o que ocorre é um redimensionamento da ação política, tendo em vista que surgem novas prioridades programáticas: a extensão territorial, o cálculo estatístico e a população. O que pretendemos ressaltar é que "se não há uma contradição entre as análises do poder disciplinar e aquelas relativas ao conceito de biopoder, na medida em

\footnotetext{
${ }^{5}$ De acordo com Edgardo Castro, "a questão da biopolítica encontra em Foucault quatro desenvolvimentos que não são completamente integrados entre os anos [1974]-1979" (CASTRO 2008, 190). Deste modo, o autor nos dá margem para sugerir que a genealogia foucaultiana varia conforme o campo de estudo: medicina social, "racismo", soberania e "governamentalidade".
} 
que ambas tomam os processos de normalização como sua base comum, não se pode deixar de notar que tal conceito impôs uma ligeira mutação no curso das pesquisas genealógicas de Foucault" (DUARTE 2006, 48, grifos meus). Como salienta Machado, a análise genealógica da gestão das populações, ou seja, "a questão do governo considerado como um conjunto de procedimentos destinados a dirigir a conduta dos homens se apresenta de dois modos: como poder pastoral e como razão de Estado" (MACHADO 2006, 178. 179). Deste modo, a nova problemática reside no projeto de realizar uma "genealogia do estado moderno" (FOUCAULT 2004, 362) ${ }^{6}$ sem, no entanto, deixar de repousar sobre o binômio saber-poder, a normatividade das condutas e a dimensão econômica.

Com isso, instaura-se uma racionalidade que, por um lado, vincula a "arte de governar" à instauração de políticas de alcance social (no qual se destacam problemáticas de cunho estatístico, demográfico, econômico, higiênico etc.) e, por outro lado, serve de fundamento para as Ciências Sociais, tendo em vista que envolve um conhecimento específico a respeito daqueles que são governados, ou seja, da População. Essa mudança de enfoque fica clara no caso da sexualidade: de alvo de uma "vigilância permanente" por parte dos representantes da ortopedia mental (médicos, educadores, psicólogos etc.) torna-se um problema de saúde pública devido aos seus efeitos procriadores. Em termos genealógicos, ocorre um deslocamento da Disciplina para o Governo. "Doravante, Foucault entende que as relações de poder consistem num campo de ações de múltiplas possibilidades, porém de uma mesma natureza" (CANDIOTTO

\footnotetext{
${ }^{6}$ Michel Senellart $(2004,382)$ menciona também uma "genealogia do biopoder".
} 
2010b, 37), o que resulta numa arte de governar que toma como objeto indistintamente "[a] si próprio, almas e condutas, crianças, Estados” (FOUCAULT 2004, 92).

A nova inflexão reside no fato de que as análises histórico-filosóficas de Foucault deixam de incidir exclusivamente sobre determinados espaços institucionalizados destinados ao ensino, ao trabalho, ao tratamento médico, ao isolamento (voluntário ou correcional), ao treinamento militar - e se voltam para dispositivos de segurança, gestão e regulação. A genealogia foucaultiana passa, doravante, a estar subordinada ao desenvolvimento de uma Arte de Governar.

No início dos anos 80, a dimensão político-estratégica dos discursos - marcada pelo imperativo de normalizar as condutas - ocupa uma posição secundária diante das relações do "sujeito" consigo e com os demais indivíduos. Há, inclusive, uma "desqualificação do modelo da guerra" (KELLY apud LEMKE 2009, 75). No ensaio "O sujeito e o poder", Foucault $(1983,222)$ chega a defender que "mais do que falar de um antagonismo essencial, seria melhor falar de um 'agonismo'”. Essa concepção das relações humanas resulta da necessidade de articular o "governo dos outros" com o "governo de si mesmo". Daí Foucault tanto ressaltar a necessidade de promover, "a propósito do desejo e do sujeito desejante, um trabalho histórico e crítico", ou seja, uma "genealogia", quanto conduzir suas investigações pela tarefa de elucidar como "os indivíduos foram levados a exercer sobre eles mesmos, e sobre os outros, uma hermenêutica do desejo" (FOUCAULT 1984, 12). A função da análise genealógica passa, assim, a incidir na formação de um Si a partir de um referencial greco-romano (tendo como meta a "bela 
existência”) ou cristão (que dará origem, na modernidade, a uma "interioridade psicológica").

Essa utilização do termo genealogia, no entanto, se mostra a rigor vaga. Em primeiro lugar, a introdução de $\mathrm{O}$ uso dos prazeres não nos fornece elementos suficientes para delinearmos o que vem a ser a história genealógica no caso de um estudo sobre a problematização ética do homem do desejo. Ficamos, na verdade, sem saber se há continuidade ou não com os anos 70. Se bem que Foucault dá a entender que a "genealogia da ética" tem raízes bem extensas, pois "encontra-se no ponto de cruzamento de uma arqueologia das problematizações e de uma genealogia das práticas de si” (FOUCAULT 1984, 21).

Outro aspecto a ser destacado é que essa modalidade de investigação genealógica considera indispensável realizar um deslocamento teórico "para analisar o que é designado como 'o sujeito"” (FOUCAULT 1984, 13). Ou seja, o genealogista aborda os processos de formação da subjetividade, sem considerá-la uma instância originária, fundante ou essencial. Mas, não poderíamos considerar essa postura uma invariante nas pesquisas histórico-filosóficas de Foucault? Por fim, enquanto a questão dos dispositivos disciplinares conjugava a genealogia com o elemento força, na questão das técnicas de si, tem-se o elemento verdade, o que aponta para uma direção não apenas inédita como também portadora de resultados ainda imprevisíveis, como veremos na última etapa da obra de Foucault.

Nos três últimos anos dos cursos no Colégio de França, ocorre uma série de considerações a respeito da noção de parresia (o "falar francamente"). São estudos que não apenas foram subitamente interrompidos com a morte de Foucault 
como também ainda se encontravam numa fase embrionária. Neles, verificamos uma espécie de genealogia do uso corajoso da palavra, onde aquele que a profere - o parresiasta - coloca a si mesmo numa posição de risco, como o mensageiro no momento em que transmite aquilo que lhe foi confiado. A "problematização da parresia", que, é a etapa final da trajetória genealógica de Foucault, consiste em investigar "a questão da importância de dizer a verdade, de saber quem está habilitado para dizer a verdade e por que deveríamos dizer a verdade"; trata-se do primeiro passo no sentido de "construir uma genealogia da atitude crítica da filosofia ocidental" (FOUCAULT 2001, 65).

O desafio da fala-franca se dá no contexto das práticas do Governo de $\mathrm{Si}$, o que significa dizer que a questão da verdade passa a estar vinculada diretamente ao projeto de uma Estética da Existência. Aliás, de acordo com um relato de Veyne (1986, 935), Foucault teria considerado Nietzsche o precursor da confluência entre discurso verdadeiro e estilo de vida: ele "gostava de repetir que a filosofia de Nietzsche não é uma filosofia da verdade, mas do dizer-verdade". A enunciação de discursos parresiásticos não é abordada a partir de um registro lógico-epistemológico, mas sim dentro da perspectiva do bios, ou seja, diz respeito ao "modo como se vive", à "maneira de se conduzir [...] ao longo da existência" (FOUCAULT 2009, 148).

Em A coragem da verdade (1984) é Sócrates quem aparece como símbolo dessa atitude ético-filosófica de descobrir "as opiniões verdadeiras que se deve seguir e as opiniões falsas das quais devemos manter distância" (FOUCAULT 2009, 101), condição indispensável para desenvolver uma conduta autêntica e incorruptível. Com isso, "os discursos são qualificados de verdadeiros se atuarem como princípios 
e matrizes de ação de modo a formar no indivíduo a atitude crítica para enfrentar os acontecimentos da existência" (CANDIOTTO 2010a, 148). Nessa etapa das investigações foucaultianas, a Verdade surge, acima de tudo, como um elemento imprescindível ao projeto de autotransformação do próprio "sujeito". "Alterar o valor da moeda" (lema do antigo quinismo $)^{7}$ será a última palavra das pesquisas genealógicas de Foucault. E seu efetivo alcance talvez dificilmente possa ser completamente elucidado.

Abstract: In this paper I intend to consider the various inflexions through which passes the Nietzschean concept of genealogy in Michel Foucault's work throughout the 1970s and 1980s. I wish to point out that the genealogical procedure is modified according to the addressed subject, i.e. it does not share the same theoretical and methodological assumptions when it is focusing (1) the rejection of the metaphysical notion of an essential origin; (2) the relationship of reciprocity between Knowledge and Power; (3) the project of transforming human life into a sort of work of art and, finally, (4) the developing of an idea of truth divorced from logical, epistemological or ontological parameters.

Keywords: history; power; ethics; truth.

\section{REFERÊNCIAS}

ANSELL-PEARSON, Keith. The significance of Michel Foucault's reading of Nietzsche: power, the subject, and political theory. In: SEDGWICK, P. R. (Ed.). Nietzsche: a critical reader. Oxford: Blackwell, 1995, p. 13-30.

CALOMENI, Tereza Cristina B. A singularidade da genealogia de Michel Foucault. In: CALOMENI, M. T. B. (Org.). Michel Foucault: entre o murmúrio e a palavra. Campos, RJ: Editora Faculdade de Direito de Campos, 2004, p. $39-77$.

${ }^{7}$ Utilizamos essa grafia para evitar associações inadequadas com o cinismo moderno. 
CANDIOTTO, Cesar. Foucault e a crítica da verdade. Belo Horizonte: Autêntica; Champagnat: Curitiba, 2010a (Capítulo V: "Verdade e ética do sujeito", p. 123-154).

Ética e política em Michel Foucault.

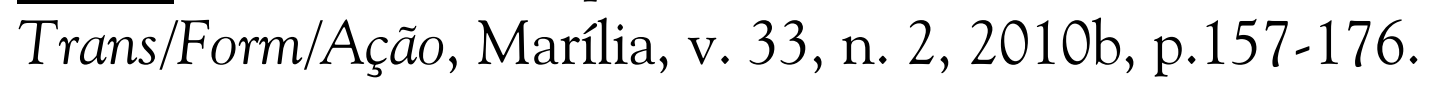

CASTRO, Edgardo. Biopolítica: de la soberania al gobierno. Revista Latinoamericana de Filosofía, v. 34, n. 2, primavera de 2008, p. 187-205.

DELEUZE, Gilles. Nietzsche et la philosophie. Paris: PUF, 1962.

DUARTE, André. Biopolítica e resistência: o legado de Michel Foucault. In: RAGO, Margareth; VEIGA-NETO, Alfredo. Figuras de Foucault. Belo Horizonte: Autêntica, 2006, p. 45-55.

FONSECA, Márcio Alves da. Entre a vida governada e o governo de si. In: ALBUQUERQUE JR., Durval Muniz de; VEIGA-NETO, Alfredo; SOUZA FILHO, Alípio de. (Orgs.). Cartografias de Foucault. Belo Horizonte: Autêntica, 2008, p. 241-251.

FOUCAULT, Michel. L'usage des plaisirs (Histoire de la sexualité, t. II). Paris: Gallimard: 1984 (Coleção Tel, edição de bolso).

. La volonté de savoir (Histoire de la sexualité, t. I). Paris: Gallimard, 1976.

- Surveiller et punir. Naissance de la prison. Paris: Gallimard, 1975 (Coleção Tel, edição de bolso).

- A verdade e as formas jurídicas (cinco conferências 
de Michel Foucault na PUC-RJ). Tradução de Roberto Cabral de Melo Machado e Eduardo Jardim Moraes Rio de janeiro: Nau, 1996 [1974].

- L'ordre du discours (leçon inaugurale au Collège de France, 2 décembre 1970). Paris: Gallimard: 1971.

- Le courage de la vérité. (Cours au Collège de France: 1984). Edição organizada por Frédéric Gros. Paris: Gallimard-Seuil, 2009.

- Fearless Speech. Editado por Joseph Pearson. Los Angeles: Semiotext(e), 2001 [1983].

- Sécurité, territoire, population. Cours au Collège de France: 1977-1978. Edição organizada por Michel Senellart. Paris: Gallimard/Seuil, 2004.

- "Il faut défendre la société". Cours au Collège de France: 1975-1976. Edição organizada por M. Bertani e A. Fontana. Paris: Gallimard-Seuil, 1997.

. The Subject and Power [ensaio]. In: DREYFUS, Hubert; RABINOW, Paul. Michel Foucault: beyond structuralism and hermeneutics. 2a. ed. Chicago: The University of Chicago Press, 1983, p. 208-226.

. La volonté de savoir [resumo de curso]. In:

Dits et écrits (1970-1975). Volumes II. Paris: Gallimard, 1994a, p. 240-244.

- Nietzsche, la généalogie, l'histoire [ensaio]. In: Dits et écrits (1970-1975). Volumes II. Paris: Gallimard, 1994b, p. 136-156.

GEISS, K-H. Foucault, Nietzsche, Foucault: Die Wahlver- 
wandtschaft. Pfaffenweiler: Centaurus, 1993.

KELLY, Mark G. E. The Political Philosophy of Michel Foucault. Nova York; Londres: Routledge, 2009 (Capítulo 3: "Power II", p. 55-77).

MACHADO, Roberto. Foucault, a ciência e o saber. $3^{\text {a }}$ ed. revista e ampliada [de Ciência e saber: a trajetória da arqueologia de Foucault, 1982]. Rio de Janeiro: Jorge Zahar, 2006 (Capítulo "As genealogias", p. 167-181).

MACINTYRE, Alasdair. Genealogies and subversions. In: SCHACHT, Richard. (Ed.). Nietzsche, genealogy, morality: essays on Nietzsche's Genealogy of morals. Berkeley: University of California Press, 1994, p. 283-304.

MAHON, Michael. Foucault's nietzschean genealogy: truth, power, and the subject. Albany: State University of New York Press, 1992.

NIETZSCHE, Friedrich. Genealogia da moral: um escrito polêmico [em adendo a Além do bem e do mal como complemento e ilustração]. 2 ${ }^{\mathrm{a}}$ ed. Tradução de Paulo César de Souza. Rio de Janeiro: Brasiliense, 1988 [Zur Genealogie der Moral: Eine Streitschrift, Dem letztveröffentlichten "Jenseits von Gut und Bose" Ergänzung und Verdeutlichung, 1887].

RAJCHMAN, John. Michel Foucault: The Freedom of Philosophy. Nova York: Columbia University Press, 1985.

REVEL, Judith. Foucault, lecteur de Nietzsche. In:

Foucault, une pensée du discontinu. Paris: Mille et une nuits, 2010, p. 86-92 [versão modificada de Expériences de la pensée: Michel Foucault. Paris: Bordas, 2005]. 
SCHRIFT, A. D. Nietzsche's French Legacy: A Genealogy of Poststructuralism. Nova York; Londres: Routledge, 1995 (Capítulo 2: "Foucault: Genealogy, Power, and the Reconfiguration of the Subject", p. 34-58).

SENELLART, Michel. Situation des cours. In: FOUCAULT, M. Sécurité, territoire, population. Paris: Gallimard/Seuil, 2004, p. 379-411.

THIELE, Leslie Paul. The Agony of Politics: The Nietzschean Roots of Foucault's Thought. The American Political Science Review, vol. 84, n. 3, setembro de 1990, p. 907925.

VEYNE, Paul. Le dernier Foucault et sa morale. Critique, n. 471-472, agosto-setembro de 1986, p. 933-941. 